cambridge.org/cty

\section{Corrigendum}

Cite this article: Chowdhury S, Chadha T, Fafard M, Shillingford M. (2018) Mechanical circulatory support using modified TandemHeart ventricular assist device in neonates with CHD - CORRIGENDUM. Cardiology in the Young 28: 1363. doi: $10.1017 /$ S1047951118001762

\title{
Mechanical circulatory support using modified TandemHeart ventricular assist device in neonates with CHD - CORRIGENDUM
}

Shamsur Chowdhury, Tanya Chadha, Mark Fafard and Michael Shillingford

doi: 10.1017/S1047951118001245, Published by Cambridge University Press, 28 August 2018.

The author apologises for the omission of Figure 1 from this article. Please see the figure below, and please note that the citation to this figure should have appeared in the Patients and methods section of the paper as follows:

\section{Patients and methods}

We modified the TandemHeart Ventricular Assist Device circuit by introducing an oxygenator (Quadrox, Maquet, Rastatt, Germany) on the outflow limb, a hemoconcentrator (Sorin Inc., Arvada, Colorado, United States of America) to the pre-oxygenator tubing and gate clamps in post-oxygenator limb (See Figure 1).

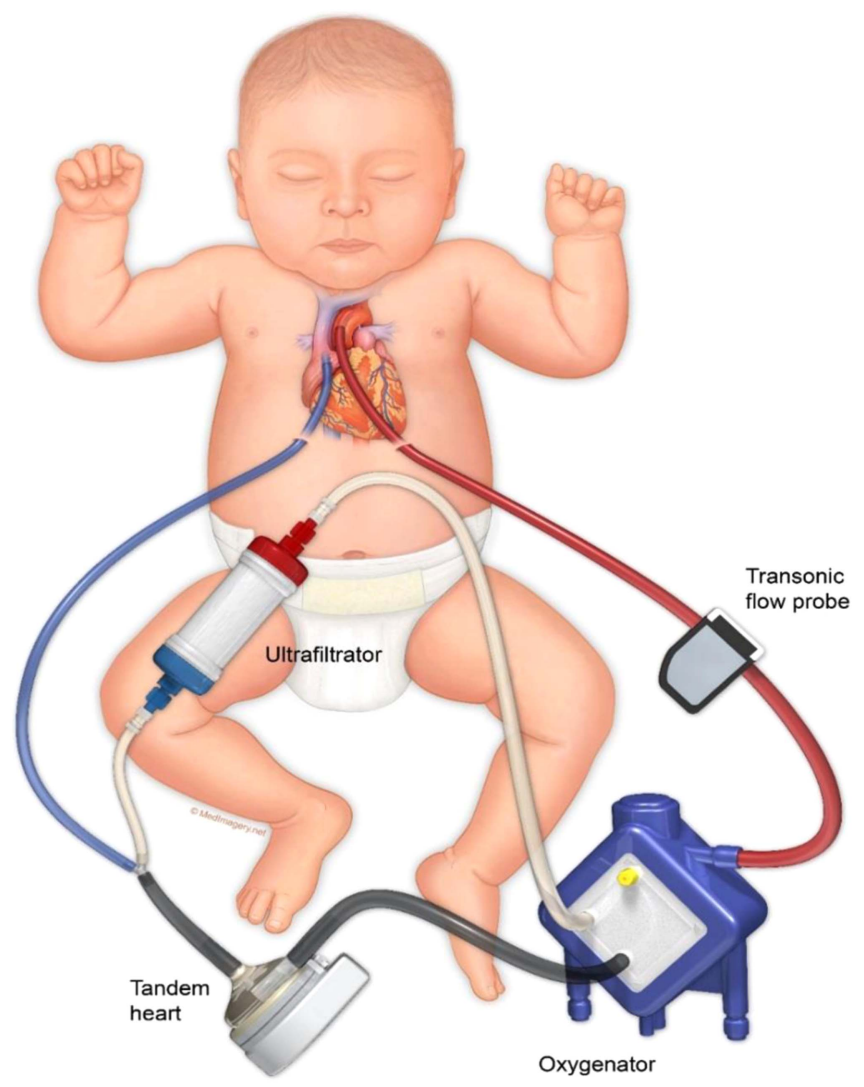

Figure 1. Modified TandemHeart VAD circuit.

\section{Reference}

Chowdhury S, Chadha T, Fafard M, Shillingford M. Mechanical circulatory support using modified TandemHeart ventricular assist device in neonates with CHD. Cardiol Young. Published by Cambridge University Press, 28 August 2018. doi: 10.1017/S1047951118001245 